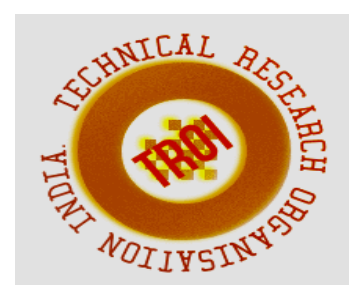

\title{
ATTENDANCE AND TIME MANAGEMENT SYSTEM USING CLOUD FOR CORPORATE COMPANIES
}

\author{
Syeda Tasmiya Tarannum ${ }^{1}$, Chaithra $C^{2}$, Soundarya V S 3 , Indhu S N ${ }^{4}$, Mohan Raj ${ }^{5}$ \\ Department Of Computer Science And Engineering \\ Dr T Thimmaih Institute Of Technology, Kolar Gold Fields 563120, Karnataka India \\ Email ID: srisony03@gmail.com
}

\begin{abstract}
Most probably the web applications are developed from the sides of web systems and these objects are extensible and high acquirable. Therefore the cloud offers the creativity of approaching boundless pool of storage with computing the network methods and their practices can be ascendible in position where as cloud computing creates computer system methods mainly in storage and computing the power in obtainable, accessible demand without direct active control by the user. Effective employee attendance management system provides any organization to enlarge over all corporate performance and to execute the specific goals for the organization. Physical attendance time checking makes more expensive of time consuming and the paper work of the companies. Human activities may result in faults so, this affects the productivity of the organization, although some existing systems will have some failures in real time attendance monitoring like flexibility and data base storage size. Further organizing the new techniques for the employee attendance cloud based systems that are integrated with NFC technology called as time attendance management system (TAMS). In this system the applications offers multiple company accounts in which each of the user can have his/her own account and containing the application with several important performances such as entering and leaving hours, real time upgrading information, and access to produce the reports. It also provides online portal service for many companies users
\end{abstract}

without any special software to install and it always allocates more adaptable data storage.

Keywords: employee attendance; time attendance management system; NFC; cloud computing

\section{INTRODUCTION}

Freshly, most of the companies or organizations want a system to record the employee attendance data. The detailed and correct employee attendance data is very important for managing employees administration and development. Generally, the employee attendance is using manually by the paper based attendance sheet system. In the manual attendance system the company manager barely maintains the employees updated information and calculates their working hours and performance. In commonly, the supervisor adds the working hours by using the employees attendance ti e card and fills in the time sheet by indicating number of employees working hours for every week or each period of the time. This process takes inefficient time consuming in attendance records calculation, employee time shifts management, every in/out time tracking, and high cost of the paper sheet [1], [2].

To improve the employees attendance tracking and time management system using current technologies for person identification that is radio frequency identification (RFID) and bio metric technologies such as finger print identification. The biometric system is employed to validate the person approval or 
permission. However, there are some limitations of the biometric system. The fingerprint attendance system has a problem of human physical contact. The fingerprint sensor usually touched by a lot of people may cause some disease infects. Dryness or dirty of the finger skin probably make inaccuracy of the matching results. The image captured of finger demands a large memory space so that the system has slow running time when the volume of employee data highly grows. The memory device used to store employee data in many separate locations and make the data management more difficult.

In other hand the contactless attendance checking device that is radio frequency identification (RFID) and near field communication (NFC) technologies gives more efficiency of flexible data integration, and more efficient cost in commercial and industrial use. NFC is a newer version type of RFID which is currently integrated with mobile devices in two way communication between NFC tags and reader. RFID itself is mainly used in identification and tracking applications i.e. inventory, package tracking, highway toll gate, while NFC is used for more practical and data secure transaction i.e. person identification, payment system, or other contactless access control. NFC is also fixed in smart phones to support the new trends of life styles such as buying tickets, access the room lock, parking, check-in at the airport, and business cards exchanges. The NFC and RFID applications and implementations were described in [5], [6], [7].

Some of the other employee attendance systems using different technologies have been proposed. Three time attendance systems were discussed as followed. Firstly Cloud Time and Attendance System [8] uses the fingerprint reader to capture the employee data and transmit the data to server through Internet communication and also includes door lock control and data backup. However, the system has some limitations of the identification speed. For verifying a single fingerprint, it must check the one with all other templates stored in the database server that is time consuming [9]. Secondly, First Time Attendance Management [10] was designed for a small-size company That is $10-20$ employees. This application uses LAN based and USB storage to transfer employees attendance data from the fingerprint scanner to the local server. It also allows manager of the company to generate and view the time attendance reports and manage employee information and their attendance data records, after all this module cannot be accessed online. Thirdly attendance system namely,UA300 system also uses the fingerprint module but it does not provide online services. The proposed system uses the concept of NFC to control the attendance system with wireless when maintaining the private and security of the system. NFC is implemented through the RFID card. It uses a microcontroller to store database, RFID is tagged to store the identification data.

All industries can benefited by using the attendance system more flexibility and low cost in terms of hardware and software infrastructure. Therefore, the cloud-based time and attendance tracking system comes to our attention. Recently, the cloud technology has been integrated with the employee attendance system for more efficiency of data management though the visualization technology [13].

The cloud based sys-tem can be accessible through a web interface and all database can be stored on servers with more secure connection and regular backups. It also allows the data to be viewed, modified, report and analyzed. The research [14] proposed a cloud-based time and attendance system which allows employees to login and out over the web, enables employees and managers to monitor time and compliance, schedule staff, and run reports.

\section{OBJECTIVES}

Now the generation is moving faster and faster in the field of technologies and numerous technologies are abiding us according to our necessaries and one of them is employee time and management system in the corporate field. However the proposed system of closed -based time and attendance system which allows (or) enables employees and managers to login and out over the web, enables employees and manager to monitor time and compliance, schedule staff, and run reporter and this system uses technologies such as RFID and NFC and also door locking mechanism the proposed system provides accurate employees attendance data which is very necessary for maintaining the employee 
supervision and discipline and increases organizations productivity.

\section{EXISTING SYSTEM}

Some of the existing employee attendance system uses different technologies let us discuss them. In some technology uses cloud-TAMS (Time attendance and management system )which uses the finger print reader to capture the corresponding employees data and transmit the data to server through internet. However this have limitation such as identification speed i.e. verifying a single finger print, it must check the one with all other templates stored in the data base server which is time consuming .One more existing system first time attendance management was designed for a small-size company i.e. 10-20 employees. This application uses LAN-based and USB storage to transfer employees from the fingerprint scanner to the local server. However the information cannot be accessed through online to overcome the drawbacks of identification speed cost of system devices, real-time attendance monitoring and flexibility of database storage size.

\section{PROPOSED SYSTEM}

In this paper, our proposed system has been developed based on the Software Development Life Cycle (SDLC) which is the one of the popular software development method. For the customer satisfaction, the proposed application was evaluated with Expectancy Disconfirmation Model.

\section{A. Software Development Life Cycle (SDLC)}

The SDLC is a process used to produce a highquality software which meets the customer expectations within times and cost estimation. The development process of the proposed timeattendance management system is described in a series of seven main phases consisting of planning, analysis, design development, testing, implementation and maintenances as follows.

1) Planning phase: The development of the proposed ap-plication has been performed within 4 months as shown in the timeframe of Figure 1. Since the purpose of our system is to support the time attendance management of any organizations and their employees, we established the survey to collect the user requirements in the form of questionnaire.
User Requirement The end user's needs and intended uses were gathered from several company managers and staffs as described in Table II. During requirement identification, we had taken into account two main system features consisting of input and output specifications. The Input part of the system is designed for the user registration, employee information man-agement, and NFC tag data management. The output functions enable generating various reports, setting up clock schedule, and managing the company and employee data storage.

Functional Requirements The operation of the system for data manipulation and processing should include creating and modifying the user accounts and enabling search options of the employee details. Other specific functionalities should accomplish creating shift and associate policies, assigning shift to employees, tracking every employee's in-out time .

Non-Functional Requirements The qualification aspects of the system should be concerned such as performance requirements, security, or reliability. Based on the quality requirement, our system should provide the feature of system recovery and backup, automatically logging out after 15 min-utes of none active use and the function to display help text, tips, or suggestions.

2) Analysis phase: At this phase, our system functionalities are defined. There are various main functions consisting of user registration, user login authentication, realtime attendance information view, company and its employee profiles man-agement, attendance captures with NFC scanner, shift policy assignment, automatically calculation of leave, late, overtime from recording entries and exits, and generate reports. A proper use case diagram describes a high-level overview of the relationship between the user and the different use cases to achieve the stated functions. The use case diagram in Figure 2 shows how the main components of the system interact with the involved people consisting of the company manager, employees, and system administrator. 
Administrator: The administrator of the system is the highest level user. The administrator can manage user accounts and profiles such as approved changes to basic employee information (duty hours, type of duty, alter-native work schedules, name changes, etc.). The other authorized users i.e. employee and manager are assigned by the administrator to do some specific tasks in the sys-tem. For the main features of the attendance management system, the administrator can create and perform the time keeping management together with the NFC technology. The personal identification numbers for each employee is assigned and stored in the NFC card given to the employee of the company.

Company Manager: Manager of any company can firstly register then login or out to the system. The important system features are provided for the manager i.e. creat-ing and assigning separate shifts for different types of employees based on departments, defining the attendance policies, tracking every employee in/out time, and generating weekly, monthly, and yearly reports. Employee of the company: With attendance monitoring module, an employee of any company can do the reg-istration and receive an NFC card with an identification number. Every employee will use the NFC card to mark entering or leaving time stamps. They also login or out to view their own attendance records, profiles as well as update their personal information. Since the proposed time attendance system is based on cloud technology, all users can access the application through the internet communication. As mentioned earlier, the proposed system can be used in any companies or organizations to monitor their employees' working time with three user roles. When the employee scans the NFC card, all details of the employee attendance i.e. ID, photo, date, time-in and time-out is transmitted using NFC communication modes. The employee's identity is searched in the database with the scanned data. The system then validates the person information and marks the presence with the current data and time. The application can repeat the steps above for all present employees.

Since the proposed time management application is devel oped based on cloud computing, the data storage is built using the enterprise Microsoft SQL Server which provides the appli-cation and database services on cloud. Our system is developed in the web-based application with user responsive interface design which supports the web site to display the same content to all devices with different styles of the resolution screens. Hence the users can access the application using any devices from any places.

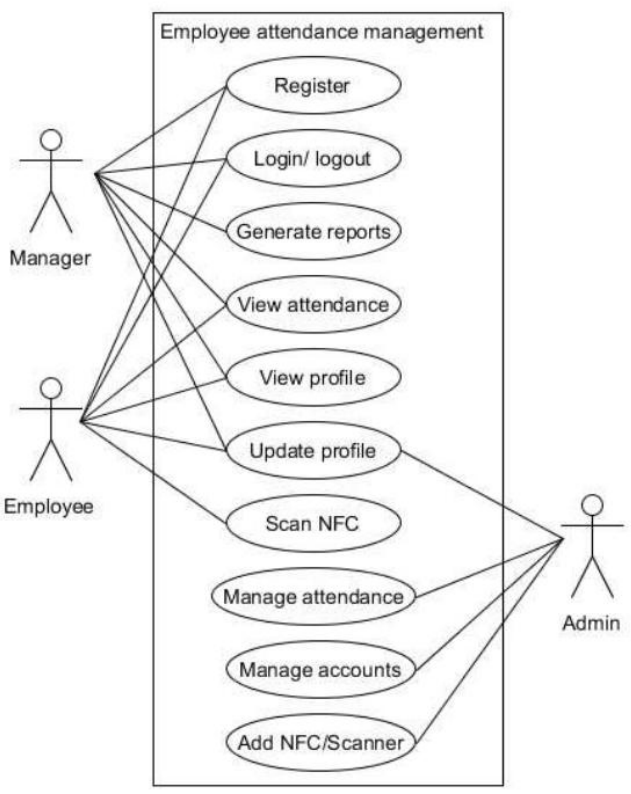

Figure1: usecase diagram of proposed system

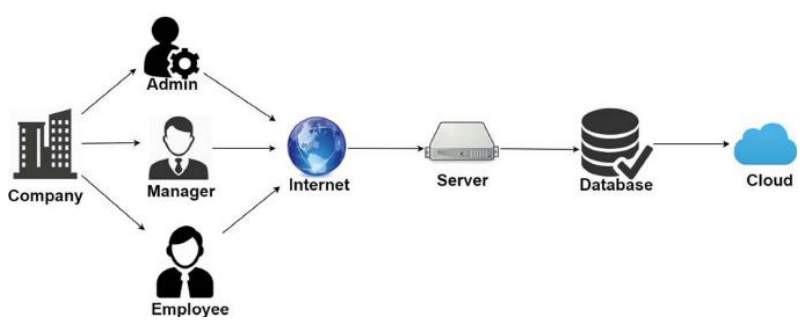

Figure2: overview of the prposed TMS architechure

3) Design Phase: In the design phase, the specific designs and workflows for our application to accomplish the user requirements are identified. The proposed system features are described in the user interface design and application archi-tecture. The user interface should make the user interaction as simple and effective. To support our different types of user i.e manager, employee, and administration, the proposed application shows individual system appearance for each type of them after they login.

A Home page: The first page of our webbased application provides the main features for accessing to the system i.e. the registration, login and logout, search, and the company contact 
B Attendance Records Page: As shown in Figure 5, this page is used to view the employee attendance records by all users. It shows the time tracking of employee's entry and exit in daily routine work. The month drop-down can be chosen to view the daily attendance listed in the duration of the selected months. The individual employee attendance information can also be searched and viewed in this page.

C Employee Attendance Report: The employee atten-dance data is valuable for the companies as the data can be generated the relevant reports as shown in Figure 6. Hence our proposed web-based application offers a wide range of reports to facilitate the managers to access real-time attendance data such as time in, time out, overtime data, late entry, early exit). The program also provides the list of reports with various filtering options i.e. summary report by Employee which provides a daily total of the hours for a specific employee. The attendance report can be produced in form of bar chart for the summary in weekly, monthly, and yearly.

4) Development phase: Based on the previous system design documents, the application development is divided in modules and the coding is actually started. This phase includes building, installation, configuration, testing, and finding defects and error. Our program was written in PHP language since it is the open sources which provides reasonable and customized server cost. For simple implementation and maintenance, we use Model-View-Control (MVC) framework and MySQL database system allowing efficient code reuse and parallel

5) Testing phase: Software testing is investigated to present stakeholders about the qualification of the software prod-uct [16]. To ensure our proposed system having correctness and completeness, the software testing is performed by us-ing Expectancy Disconfirmation model to measure the user satisfaction. The results to be considered include that the system should meet the owner requirement and satisfaction, and system improvement should satisfy the client desires after evaluation in terms of navigation, design, architecture and ease of use. The model was represented in survey which contains the questions corresponding to the expected result evaluation.

The survey with a Likert scale (5-point scale) questions is used to evaluate our proposed system performance. Our questionnaire ask the target users to give their quantitative value in five levels of agreement as follows.

level 5 = strongly agree

level 4 = agree

level 3 = uncertain

level 2 = disagree

level 1 = strongly disagree

The questionnaire contains 5 parts consisting of Navi-gation, Organization, Ease of use, Design, and Content.

6) Implementation phase: Once the proposed time atten-dance management system has been completed, we deploy the entire database and the application code on the cloud server. However some specific changes can be deployed in further.

7) Maintenance phase: After the application is in fully operation, the software may need to address changes in the needs of the company to correct bugs or security issues. During the maintenance phase, the proposed application may include programming updates, handling bugs and error, monitoring the system performance, and adding increased functions.

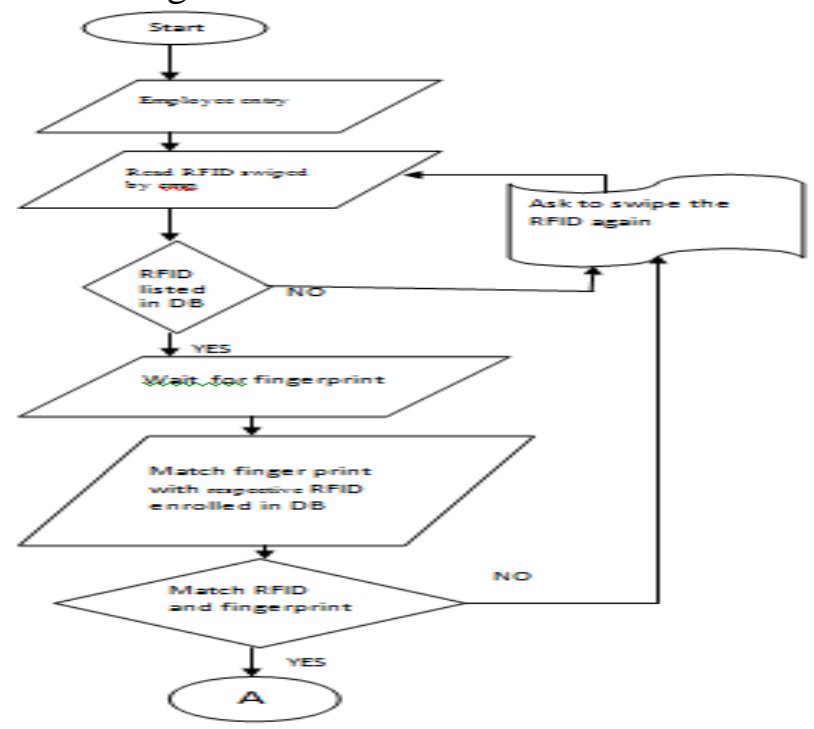

Figure 3: Architecture

\section{CONCLUSION}

We have introduced the employee attendance cloud-based system which is integrating with NFC technology, called as TAMS. And our proposed application offers multiple company accounts in which each user has its own account .In our implementation we provide online access to the uses and to manage the employee attendance data that allows to view ,modify, report and analyze, it allows provides more flexibility and lower cost 
system resources and mainly we have integrated cloud platform in this technology because the web interface and data base are stored in the cloud servers they help with more access security and backups of the lost database, for the better results we use of RFID and NFC technology in TAMS.

\section{REFERENCES}

[1] M. Salah Uddin, S. M. Allayear, N. C. Das, and F. A. Talukder, "A location based time and attendance system," International Journal of Computer Theory and Engineering, vol. 6, pp. 36-38, 012014.

[2] W. A. Al-tarawneh, "The impact of transaction processing systems in making operational decisions: a case study of computerizing the employees affairs department of al-balqa applied university," European Scientific Journal, vol. 11, pp. 188203, March 2015.

[3] M. Dalah Chiwa, "Secured employee attendance management system using fingerprint," IOSR Journal of Computer Engineering, vol. 16, pp. 32-37, 012014.

[4] O. Akinduyite, A. Adetunmbi, O. O. Olabode, and O. Ibidunmoye, "Fingerprint-based attendance management system," Journal of Com-puter Sciences and Applications, vol. 1, pp. 100-105, 112013.

[5] D. Wijaya and I. Asror, "Integrated and efficient attendance manage-ment system based on radio frequency identification (rfid)," Interna-tional Journal of Electronic Commerce, vol. 73, pp. 149-154, 2015.

[6] G. Arcese, S. Flammini, G. Campagna, and O. Martucci, "Near field communication: Technology and market trends," Technologies, vol. 2, pp. 143-163, 092014.

[7] G. Jain and S. Dahiya, "Nfc: Advantages, limits and future scope,"International Journal on Cybernetics and Informatics, vol. 4, pp. 112, 082015.

[8] "Time and attendance system on the cloud," http//www.cloud-ta.com/HowItWorks.aspx, accessed: 2017.

[9] J. Chandramohan, N. Ramalingam, M. Ashok kumar, T. Dineshkumar, G. Kannan, and R. Prakash, "Attendance monitoring system of students based on biometric and gps tracking system," International Journal of Advanced engineering, Management and Science, vol. 3, pp. 241-246, 012017.

[10] "First time attendance management," http://www.fingerthailand.com/firsttime. aspx, accessed: 2017.

[11]O. Puja Rani, "Smart wireless attendance monitoring using nfc," In-ternational Journal for Research in Applied Science and Engineering Technology, vol. 3, pp. 281-287, 2015.

[12]V. More and S. Nayak, “Attendance automation using near field communication (nfc) technology,” International Journal of Scientific and Engineering Research, vol. 3, pp. 572575, 122013.

[13]Y. Gao, X. Hu, L. Peng, H. Liu, and F. $\mathrm{Li}$, "A differential evolution algorithm combined with cloud model for rfid reader deployment," in The Fourth International Workshop on Advanced Computational Intelligence, 2011, pp. 193-198.

[14]T. Sharma and S. L. Aarthy, “An automatic attendance monitoring system using rfid and iot using cloud,” in 2016 Online International Conference on Green Engineering and Technologies (IC-GET), Nov 2016, pp. 1-4.

[15]K. M., E. Basar, M. Celikag, E. Atasoylu, and M. S, "An automated attendance monitoring and registration system for emus spike seminar series," in 2nd International Conference on 2nd International Confer-ence on Integration of Information Technology in Science Education, 01 2007, pp. -.

[16]J. Barsky, "Customer satisfaction in the hotel industry: Meaning and measurement," Hospitality Research Journal, pp. 51-73, 1992.

[17]N. Elkhani and A. Bakri, "Review on expectancy disconfirmation theory (edt) model in b2c e-commerce," pp. 1-13, 2012.

[18]M. Khalifa and V. Liu, "Satisfaction with internet based services: The role of expectations and desires," International Journal of Electronic Commerce, vol. 7, pp. 31-49, 2002. 